\title{
1 Alkali treatment of hemp fibres for the \\ 2 production of aligned hemp fibre mats for \\ 3 composite reinforcement
}

4 Sunny, Tom*; Pickering, Kim L; Lim, Shen Hin

5 School of Engineering, The University of Waikato, Gate 8, Hillcrest Road, 6 Hamilton, 3240, New Zealand

$7 \quad *$ Correspondence to: Email: tomsunny54@gmail.com

8 Abstract

9 The main objective of this study was to produce aligned hemp fibre mats from high strength hemp

10 fibres using dynamic sheet forming (DSF). Alkali treatment of hemp fibre was carried out at

11 ambient and high temperature to separate fibres. Single fibre tensile testing was used to assess the

12 tensile properties of the fibres. It was found that the highest tensile properties were exhibited by

13 high temperature treated fibre, whereas the tensile properties exhibited by ambient temperature

14 treated fibre were lower than for untreated fibre. It was also found that fibre granulated after high

15 temperature treatment, was better separated than that granulated before high temperature

16 treatment. This well-separated fibre could successfully be formed into mats using DSF. The

17 orientation of the formed mat was analysed using ImageJ (NIH, USA) software by which the

18 potential of DSF to produce aligned hemp fibre mat was supported. The mechanical performance

19 of composite reinforced by these aligned hemp fibre mats were assessed.

20 Keywords: Dynamic sheet forming (DSF); Alkali treatment; Aligned fibre mats;

21 Hemp fibre

\section{1. Introduction}

23 A major area of recent technological development has been that of natural plant fibre composites

24 (NPFCs). Generally, NPFCs consist of plant fibres as reinforcement in a polymer matrix. Natural

25 plant fibres (NPFs) have undergone increased industrial uptake because of their favourable

26 characteristics such as lower density, higher specific strength and stiffness, lower cost, and with

27 lower associated hazards during manufacture (Pickering 2008, Kabir, Wang et al. 2012, Kabir,

28 Wang et al. 2013, Pickering, Efendy et al. 2015). Hemp fibres are attractive reinforcements for

29 NPFCs as they exhibit high tensile strength ranging between 550-1110 MPa (Beckermann and

30 Pickering 2008, Pickering, Efendy et al. 2015). Hemp fibres are also more environmentally

31 friendly than most fibres since they can be grown without pesticides and herbicides. 
32 The main reasons that limit NPFCs in industry are moisture absorption, lower strength and greater

33 variability of properties compared to synthetic fibre composites (Pickering, Efendy et al. 2015).

34 Previous research has shown that chemical treatments of reinforcing fibres can help to overcome

35 these limitations (Mwaikambo and Ansell 2002, Li, Tabil et al. 2007, John and Anandjiwala 2008,

36 Kabir, Wang et al. 2012, Pickering, Efendy et al. 2015). Among the different chemical treatments,

37 alkali treatment with sodium hydroxide $(\mathrm{NaOH})$ is the most widely used. This treatment removes

38 fibre constituents such as pectin, hemicellulose, lignin and waxes from NPFs bringing about fibre

39 separation and can enhance fibre properties (Beckermann and Pickering 2008, Islam, Pickering et

40 al. 2011, Pickering, Efendy et al. 2015). Modest treatments have been seen to bring about

41 increased cellulose crystallinity, which is considered to be due to the removal of the

42 aforementioned materials, whereas harsher treatments have been shown to convert crystalline

43 cellulose to amorphous cellulose and possibly resulted in chain scission (Sawpan, Pickering et al.

44 2011, Kabir, Wang et al. 2012). These alkali treatments have been carried out by different

45 researchers with varying process parameters including at ambient temperatures (AT) as well as at

46 high temperatures (HT) (Mwaikambo and Ansell 2002, Beckermann and Pickering 2008, Islam,

47 Pickering et al. 2010, Islam, Pickering et al. 2011, Sawpan, Pickering et al. 2011, Kabir, Wang et

48 al. 2012, Kabir, Wang et al. 2013, Efendy and Pickering 2014). Ambient temperature treatments

49 have many advantages such as simplicity, low cost and they can be easily carried out in large

50 volumes compared to HT treatment. However, there is limited information available on the effect

51 of alkali treatment temperature (high temperature versus ambient temperature) on the tensile

52 properties of individual hemp fibres. Also, where the tensile properties are given, these values are

53 based on variable testing regimes including: fibre bundles as opposed to single fibres and

54 unspecified gauge lengths (Beckermann 2007). Therefore, direct comparison is needed between

55 high temperature and ambient temperature treatment to inform which is best.

56 To encourage uptake of NPFCs, convenient forms of NPFs that could be used as alternatives to

57 synthetic fibre mats in standard moulding operations would be helpful. Dynamic sheet forming

58 (DSF) is a method that can be used to produce preferentially aligned short NPF mats (Sunny,

59 Pickering et al. 2017). Previous studies have demonstrated that these mats can be incorporated into

60 polymer matrices to produce composites, which exhibited higher tensile strength as well as

61 Young's modulus compared to randomly oriented fibre mats composites (Pickering and Efendy

62 2016, Pickering and Le 2016, Sunny, Pickering et al. 2017). Prior to DSF, good fibre separation is 
63 needed. Alkali treated hemp and harakeke fibres have been reported as used for the production of

64 DSF mats, (Le and Pickering 2015, Pickering, Efendy et al. 2015, Ghazali and Efendy 2016) but

65 the tensile strengths of these treated fibres were reduced compared to raw fibre due to the

66 weakening of structural components (Islam 2008, Ghazali and Efendy 2016, Le 2016, Pickering

67 and Efendy 2016). Therefore, further research is needed to develop processing parameters to

68 improve fibre separation without reduction in tensile properties of fibres prior to DSF. In the

69 current research, the alkali treatments used are modifications of selected alkali treatments from the

70 literature that report improved tensile strength for NPFs (Beckermann and Pickering 2008,

71 Oushabi, Sair et al. 2017). The data obtained for the tensile strengths of the hemp fibres were

72 statistically analysed using Weibull statistics.

\section{2. Experimental}

\section{$74 \quad 2.1$ Materials}

75 Industrial hemp fibre was obtained from Moffett Orchards Ltd., New Zealand. The bast fibres

76 were hand separated from the stalks. The chemicals used for the experiments were sodium

77 hydroxide $(\mathrm{NaOH})$ and sodium sulphite $\left(\mathrm{Na}_{2} \mathrm{SO}_{3}\right)$ supplied by Sigma Aldrich. Polypropylene (PP)

78 random copolymer SKRX3600 supplied by Clariant (New Zealand) Limited, with a melt index of

$7918 \mathrm{~g} / 10 \mathrm{~min}$ and a density of $0.9 \mathrm{~g} / \mathrm{cm}^{3}$, was used as the matrix. The coupling agent used was A-C

$80950 P$ maleic anhydride polypropylene (MAPP) supplied by Honeywell International Inc., USA

\section{$81 \quad 2.2$ Methods}

\section{$82 \quad 2.2 .1$ Alkali treatment}

83 High temperature (HT) and ambient temperature (AT) alkali fibre treatments were carried out on

84 pre-dried hand separated hemp fibres. For ambient temperature treatment, fibres were granulated

85 using an $8 \mathrm{~mm}$ mesh in a laboratory scale Castin granulator and then immersed in $5 \mathrm{wt} \%$ sodium

86 hydroxide $(\mathrm{NaOH})$ solution in a glass beaker as shown in Fig. 1a, for one (AT/one hour) or two

87 hours (AT/ two hours) with a fibre to solution ratio of 1:8. The temperature inside and outside the

88 beaker was measured using a thermometer. The measured room temperature was between $20.5^{\circ} \mathrm{C}$

89 and $22{ }^{\circ} \mathrm{C}$, whereas the temperature inside the beaker ranged from $30.5^{\circ} \mathrm{C}$ at the start of the 
90 treatment to $24{ }^{\circ} \mathrm{C}$ at the end of the treatment. For high temperature treatment, fibre and a solution

91 of $5 \mathrm{wt} \% \mathrm{NaOH}$ and $2 \mathrm{wt} \% \mathrm{Na}_{2} \mathrm{SO}_{3}$ with a fibre to solution ratio of $1: 8$ were placed in stainless

92 steel canisters (SSCs) Fig. 1b. These canisters were then positioned inside a laboratory scale pulp

93 digester controlled by a proportional-integral-derivative (PID) system as displayed in Fig. 1b,

94 which was set to operate with a time-temperature profile as shown in Fig. 2. Granulation was

95 either conducted before or after treatment. The fibres were washed after the treatments for about

9615 minutes in clean water, before being dried in an oven at $80{ }^{\circ} \mathrm{C}$ for $48 \mathrm{~h}$.

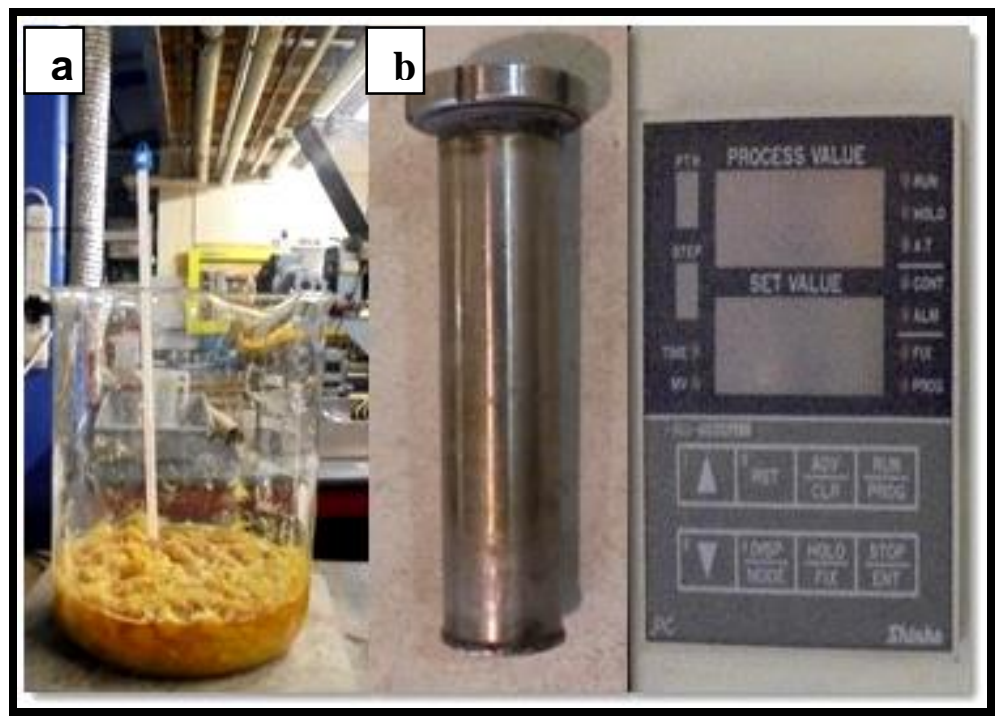

98 Fig. 1. (a) Set up used for the AT treatment (b) SSC and PID system used for the HT treatment.

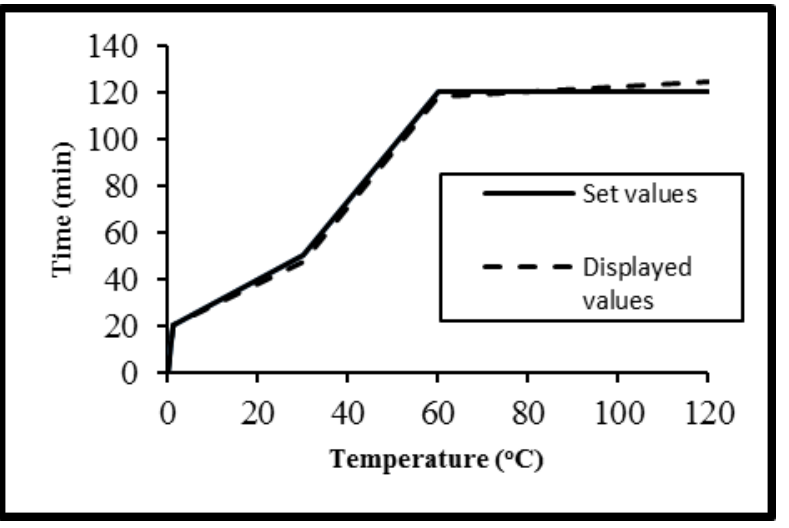

100 Fig. 2. Time-temperature profile used for the HT treatment.

\section{$101 \quad$ 2.2.2 Single fibre tensile testing}

102 The ASTM D 3379-75: Standard Test Method for Tensile Strength and Young's Modulus for

103 High-Modulus Single-Filament Materials (ASTM 1986) was followed to determine the tensile

104 strength and Young's modulus of untreated (UT), AT/one hour treated, granulated before HT

105 treated and granulated after HT treated hemp fibres. The untreated fibres were soaked in water for 
107 mounting tabs with a gauge length of two millimetres as schematically represented in Fig. 3.

108 Selected single fibres were adhered to the mounting tabs by the application of polyvinyl acetate 109 (PVA) glue.

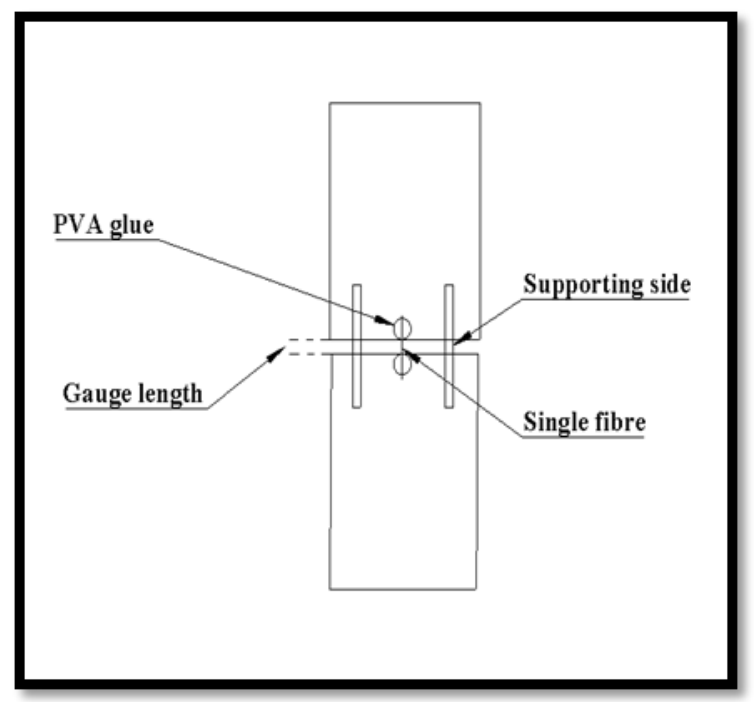

111 Fig. 3. Schematic representation of a mounting tab used for tensile testing of single fibres.

112 For the measurement of single fibre diameter, optical images were captured of single fibres as

113 shown in Fig. 4, by means of an Olympus BX60F5 optical microscope fitted with a Nikon camera.

114 The diameter was measured at five different points along each fibre (as hemp fibres have variable

115 diameters across their length) and average values were used for the calculations.

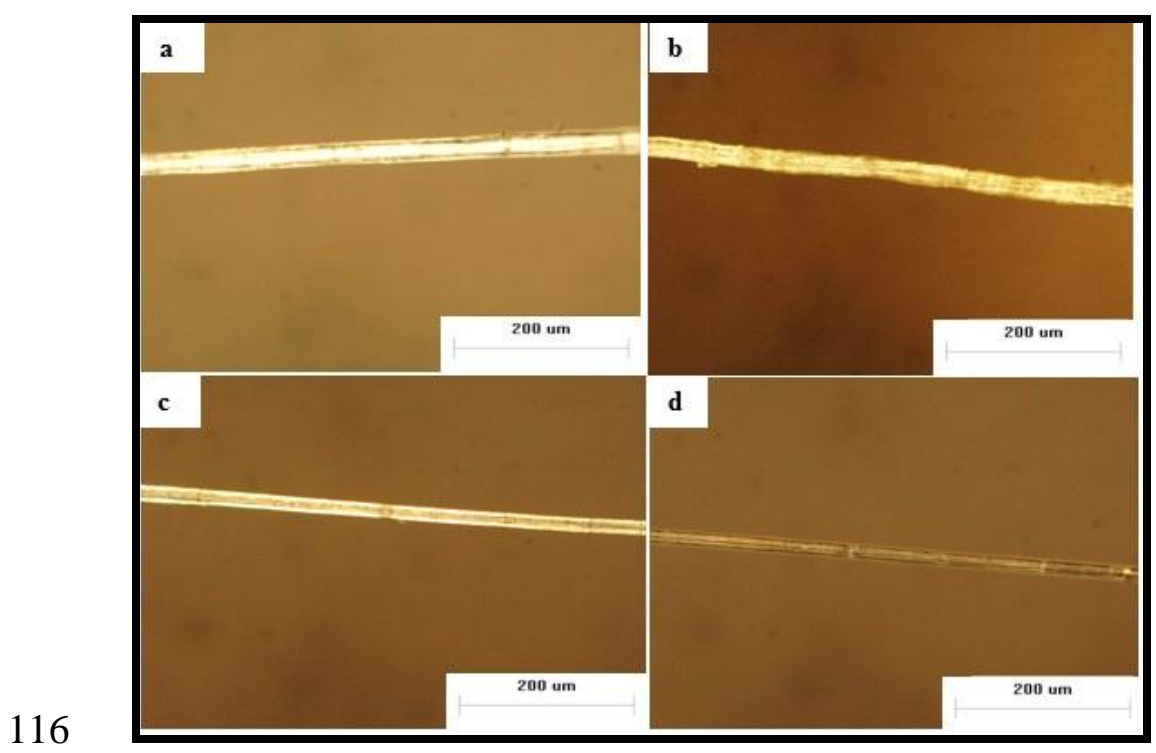

117 Fig. 4. Single hemp fibre as observed under optical microscope: (a) UT, (b) AT/one hour, (c) 118 granulated before HT and (d) granulated after HT treated hemp fibres. 
119 The single fibres were then tensile tested using an Instron-4204 universal testing machine after

120 burning off the supporting sides using a hot wire cutter. The test was carried out at a rate of 0.5

$121 \mathrm{~mm} / \mathrm{min}$ with a $10 \mathrm{~N}$-load cell. Thirty samples were tested for each treatment and system

122 compliance was determined experimentally to obtain Young's moduli according to the procedure

123 described in ASTM D 3379-75. For this, mounting tabs with gauge lengths of 5, 10 and $15 \mathrm{~mm}$

124 were also prepared.

125 The Weibull distribution is commonly used to analyse the strength variation for natural fibres

126 (Biagiotti, Puglia et al. 2004, Pickering, Beckermann et al. 2007, Zafeiropoulos and Baillie 2007,

127 Efendy and Pickering 2014). Here, the rearranged two-parameter Weibull cumulative distribution

128 expression (Biagiotti, Puglia et al. 2004, Pickering, Beckermann et al. 2007), as shown below was

129 used to analyse data obtained for different single fibre testing statistically.

$130 \ln \ln \left(1 /\left(1-\mathrm{P}_{\mathrm{f}}\right)=\mathrm{w} \ln \sigma-\mathrm{w} \ln \sigma_{\mathrm{o}}+\ln \mathrm{L}\right.$

131 where $w$ is the Weibull modulus (shape parameter) and $\sigma_{0}$ characteristic strength (scale parameter).

132 These parameters are important as they describe the variability of the fibre failure strength

133 (Zafeiropoulos and Baillie 2007). A Weibull plot of $\ln \ln \left(1 /\left(1-\mathrm{P}_{\mathrm{f}}\right)\right.$ versus $\ln \sigma$ provides a straight

134 line with gradient $w$ and intercept $\sigma_{\mathrm{o}}$ at $\ln \ln \left(1 /\left(1-\mathrm{P}_{\mathrm{f}}\right)=0\right.$.

135 2.2.3 Scanning electron microscopy (SEM) of hemp fibre surfaces

136 A Hitachi S-4100 SEM was used to obtain micrographs of fibres. Carbon tapes were employed to

137 mount the samples on aluminium stubs and were then sputter coated with platinum to make them

138 conductive.

139 2.2.4 Wide angle $X$-ray diffraction (WAXD)

140 To assess fibre crystallinity, a Philips X'Pert diffractometer fitted with a ceramic X-ray diffraction

141 tube was used. For the measurements, the fibres were chopped and pressed into a disk using a

142 cylindrical steel mould. The scanning range was between $5^{\circ}$ and $45^{\circ}$ by employing $\mathrm{CuK} \alpha$ radiation

$143(\lambda=1.54 \mathrm{~nm})$ with a voltage and current of $45 \mathrm{mV}$ and $40 \mathrm{~mA}$ respectively. Crystallinity index $\left(I_{c}\right)$

144 of the fibres was calculated using the Segal method (Segal, Creely et al. 1959):

$145 \quad \mathrm{I}_{\mathrm{C}}=\left(\mathrm{I}_{22.7}-\mathrm{I}_{18.3} / \mathrm{I}_{22.7}\right) \mathrm{X} 100$ 
146 where $I_{200}$ is the maximum intensity of the (200) lattice diffraction peak at a $2 \theta$ angle of between

$14722^{\circ}$ and $23^{\circ}$, and $I_{a m}$ is the minimum intensity of diffraction at an angle $2 \theta$ between $18^{\circ}$ and $19^{\circ}$

148 representing amorphous materials (Pickering, Beckermann et al. 2007, French 2014).

149 2.2.5 Fourier transform infrared spectroscopy (FTIR)

150 An FTIR Digilab FTS-40 was used to obtain infrared spectra of untreated, AT/one hour treated

151 and granulated after HT treated hemp fibres. Hemp fibre samples were ground to fine powder

152 using a Retsch MM400 ball mill. The ground powder for each sample was then mixed and

153 compressed with $\mathrm{KBr}$ (potassium bromide) using a hydraulic press by applying 8 tonnes $/ \mathrm{cm}^{2}$

154 pressure to prepare corresponding sample disc for FTIR analysis.

\section{$155 \quad$ 2.2.6 Thermal analysis}

156 Thermal gravimetric analysis (TGA) of untreated, AT/one hour treated and granulated after HT

157 treated hemp fibres was carried out using a PerkinElmer simultaneous thermal analyser STA 800.

158 Data were obtained at a rate of $10{ }^{\circ} \mathrm{C} / \mathrm{min}$ with a heating range of $40{ }^{\circ} \mathrm{C}$ to $500{ }^{\circ} \mathrm{C}$ and a static

159 airflow at $20 \mathrm{ml} / \mathrm{min}$.

$160 \quad$ 2.2.7 Fibre mat assessment

161 The OrientationJ plugin of ImageJ was used to assess the orientation of fibres in fibre mats.

162 Availability and ease of use make ImageJ attractive (Abràmoff, Magalhães et al. 2004, Schneider,

163 Rasband et al. 2012). The principles behind this analysis tool are available in the literature

164 (Rezakhaniha, Agianniotis et al. 2012, Gesellchen, Bernassau et al. 2014, Shah, Vollrath et al.

165 2015, Püspöki, Storath et al. 2016, Sunny, Pickering et al. 2018). OrientationJ can provide a fibre

166 orientation distribution profile based on the orientation of fibres within a mat analysed. The peak

167 of the profile indicates the predominant orientation of fibres within the mat.

168 Additionally, with the calculation of majority of the orientation of fibres in an image, this program

169 also calculates a 'coherency factor' to that orientation (Lewis 2016). This factor is calculated based

170 on the amount of pixels that are in line in a particular direction and is bounded between 0 and 1;

171 with 0 and 1 indicating isotropic and anisotropic orientations, respectively (Palmieri, Lucchetti et

172 al. 2015). Twenty-five images, each of aligned and random mats were used for the analysis. All 
173 the macroscopic images (Fig. 5 a and 5b) were taken using a Wild M3B stereomicroscope attached 174 with Nikon Digital DS-SMc camera.

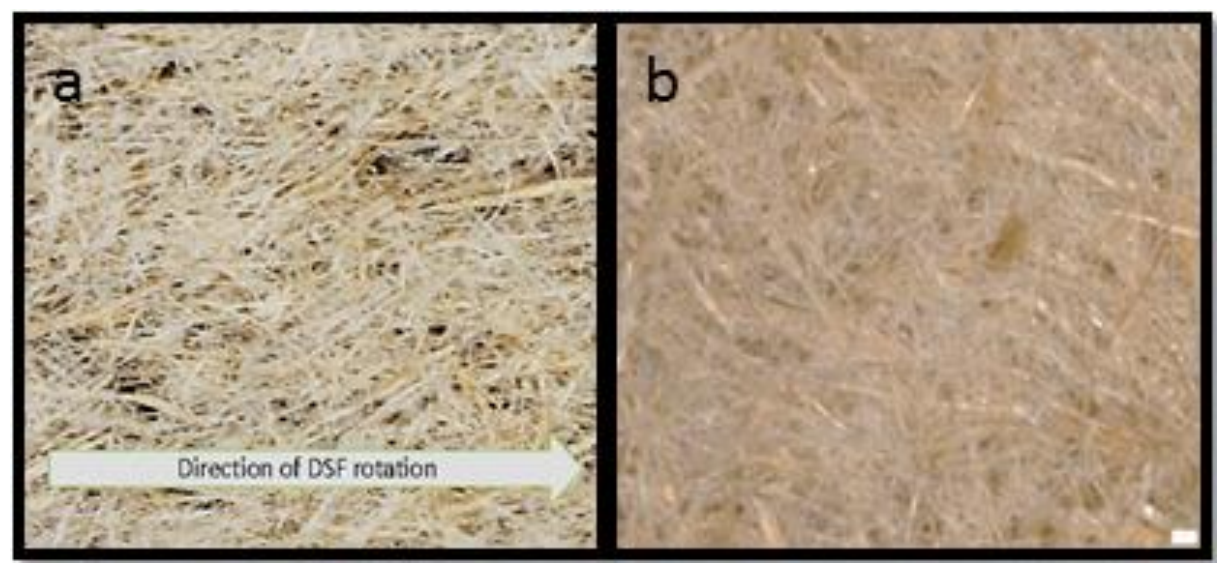

176 Fig. 5. Macroscopic images of (a) aligned short hemp fibre mat (b) random aligned mat.

\section{$177 \quad$ 2.2.8 Fibre mat production}

178 Aligned fibre mats (Fig. 6a) were produced using a dynamic sheet former (Fig. 6b) built by Canpa,

179 Canada. To produce fibre mats, fibre suspension (approx. $5 \mathrm{~g}$ in 10 litres of water) was made. This

180 suspension was then pumped by the dynamic sheet former through a reciprocating nozzle onto a

181 rotating drum covered with a wire mesh which acts as a cushion for the deposited fibre (Pickering,

182 Efendy et al. 2015). The alignment of the fibres is in accordance with the nozzle and rotation of

183 the drum. A total of $45 \mathrm{~g}$ of fibre was used for production of each mat. For the production of fibre

184 mats using DSF, well separated fibre is required to avoid blocks mainly in the flow hoses through

185 which the fibre suspension is discharged onto the rotating drum from the suspension tank.

186 Randomly aligned fibre mat was also produced by pouring fibre suspension (10g in 10 litres) onto

187 a screen with fine holes through which the water drained. The formed mat was partially drained

188 with paper towels by hand pressing. Finally, both aligned and random mats were oven dried at

$18980^{\circ} \mathrm{C}$ for 48 hours. 


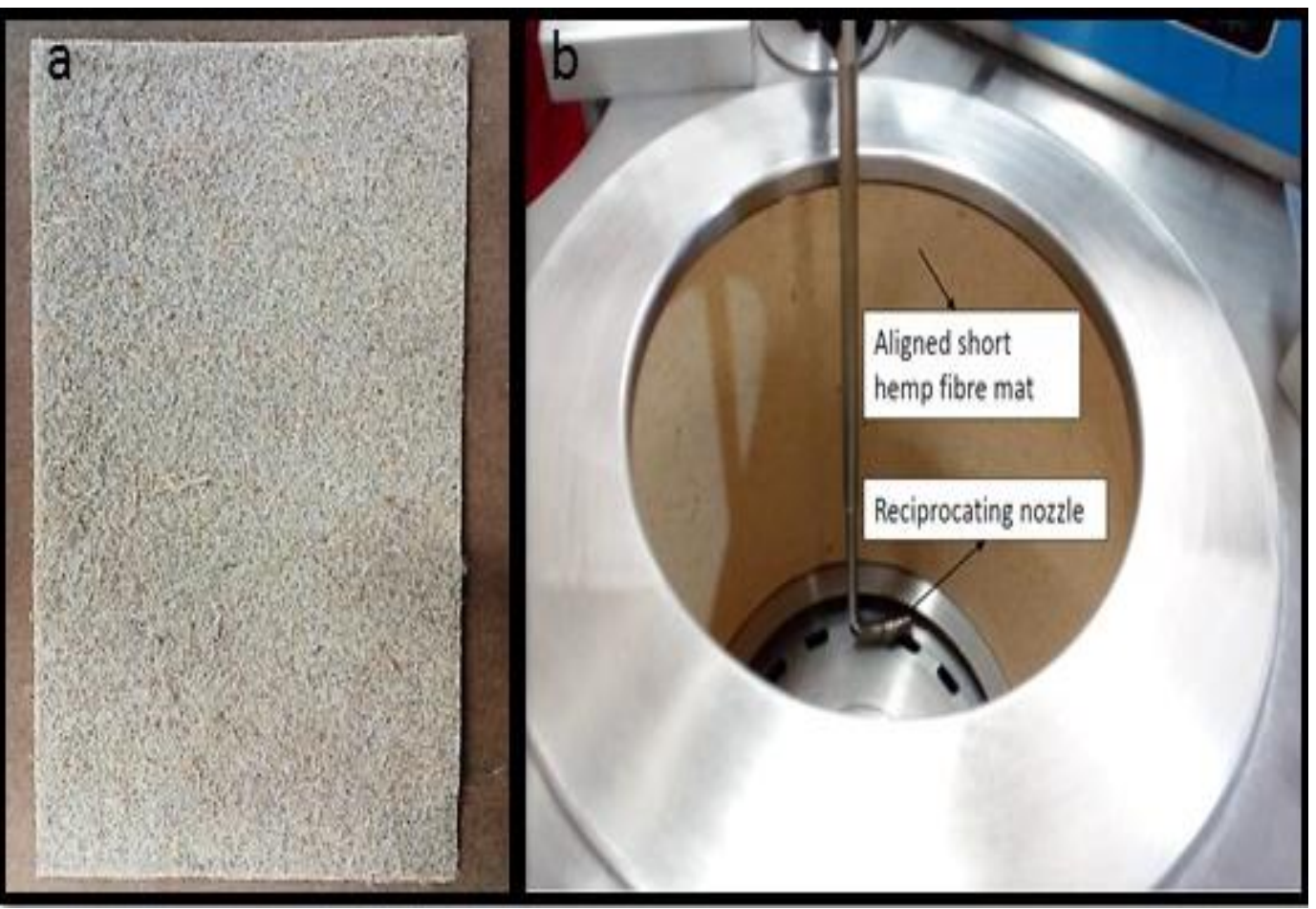

192 Fig. 6. (a) Aligned short hemp fibre mat (b) dynamic sheet former.

\subsubsection{Production of composites and testing}

194 A sheet die attached to a ThermoPrism TSE-16-TC twin-screw extruder was used to produce

195 PP/MAPP (100/7.14) sheets. In order to produce composites (except neat PP), the PP/MAPP

196 sheets and the fibre mats were weighed and arranged in stacks between two Teflon sheets before

197 inserting into a mould. The details of the mould used are available in the literature (Pickering and

198 Efendy 2016). The stacking arrangements used for the production of various composites are listed

199 in Table 1. The stacks were heated and pressed in a hot press same as that of neat PP samples (at

$200170{ }^{\circ} \mathrm{C}$ for 5 minutes at $1 \mathrm{MPa}$ ). Since the fibre mats are easily distorted, the production process

201 should be carried out carefully. Before the application of pressure, it was ensured that the sheets

202 were fully melted such that the matrix material consolidates sufficiently with the fibre mats.

203 Procedures detailed in ASTM D 638-03; Standard Test Method for Tensile Properties of Plastics

204 was followed for testing the specimens. An Instron-4204 tensile testing machine fitted with a $5 \mathrm{kN}$

$205 \mathrm{load}$ cell, operated at a constant rate of $1 \mathrm{~mm} / \mathrm{min}$ was used for the testing. For the measurement of

206 strain, an Instron 2630-112 extensometer with a gauge length $50 \mathrm{~mm}$ was attached to the central

207 part of the test specimen. Before testing, all the samples were conditioned at $23{ }^{\circ} \mathrm{C} \pm 3{ }^{\circ} \mathrm{C}$ and 

batch.

210 Table 1: Stacking arrangements used for the production of composites.

\begin{tabular}{|l|l|l|l|l|l|}
\hline \multicolumn{2}{|l|}{ Samples } & $\begin{array}{l}\text { Number of } \\
\text { PP* }^{*} \text { sheets }\end{array}$ & $\begin{array}{l}\text { Number of } \\
\text { fibre mats }\end{array}$ & $\begin{array}{l}\text { Fibre wt.\% } \\
\text { (approx.) }\end{array}$ & $\begin{array}{l}\text { Stack arrangements from } \\
\text { bottom to top of the mould }\end{array}$ \\
\hline Neat PP & 4 & 0 & 0 & PP/PP/PP/PP \\
\hline HM-15 & P $^{\#-H M-15 ~}$ & 4 & 3 & 15 & $\begin{array}{l}1 \mathrm{PP}^{*} / 1 \mathrm{MAT} / 1 \mathrm{PP}^{*} / \\
1 \mathrm{MAT} / 1 \mathrm{PP}^{*} / 1 \mathrm{MAT} / 1 \mathrm{PP}^{*}\end{array}$ \\
\hline
\end{tabular}

\section{3. Results and discussion}

\section{$213 \quad 3.1$ Tensile properties of fibres}

214 Hemp fibres have a complex layered structure, containing primary and secondary cell walls. These

215 cell walls consist of many layers of helically wound cellulose microfibrils. The main factors that

216 determine the mechanical properties of different plant fibres are cellulose content, microfibrillar

217 angle, defects and treatments. (Bledzki and Gassan 1999).

218 Table 2: Mechanical properties of hemp samples

\begin{tabular}{|c|c|c|c|c|}
\hline Hemp Samples & $\begin{array}{c}\text { Fibre Diameter } \\
(\mu \mathrm{m})\end{array}$ & Maximum Load (N) & $\begin{array}{c}\text { Average Tensile } \\
\text { Strength (MPa) }\end{array}$ & $\begin{array}{c}\text { Young's Modulus } \\
(\mathrm{GPa})\end{array}$ \\
\hline UT & $30.25(10.6)$ & $0.299(0.14)$ & $517(355)$ & $7.4(4.7)$ \\
\hline AT/one hour & $29.87(6.7)$ & $0.296(0.18)$ & $436(236)$ & $6.4(2.73)$ \\
\hline $\begin{array}{c}\text { Granulated before } \\
\text { HT }\end{array}$ & $21.38(4.3)$ & $0.252(0.08)$ & $781(428)$ & $12.04(4.4)$ \\
\hline $\begin{array}{l}\text { Granulated after HT } \\
\text { *Standard deviations are shown in parentheses }\end{array}$ & $0.2784(0.13)$ & $833(577)$ & $12.32(7.3)$ \\
\hline
\end{tabular}

220 Table 2 displays the diameters, maximum load and mechanical properties of untreated and treated

221 fibres obtained in this work. As can be seen, the HT alkali treatment (granulated before and after

222 HT) resulted in more fibre diameter reduction compared to the AT treatment. It has been found

223 that reduction in fibre diameter is due to removal of hemicellulose and lignin (Taha, Steuernagel et

224 al. 2007, John and Anandjiwala 2008, Kabir, Wang et al. 2012, Kabir, Wang et al. 2013).

225 Although no specific studies were carried out to measure the hemicellulose or lignin content in this

226 work, it has been reported elsewhere that hemicellulose breakdown occurs easily in a high 
227 temperature environment than at low temperature and the addition of $\mathrm{Na}_{2} \mathrm{SO}_{3}$ assists $\mathrm{NaOH}$ in the

228 removal of lignin (Beckermann 2007). It was found that HT treatment removed sufficient

229 hemicellulose and lignin from the fibres to give good fibre separation, whereas similar separation

230 was not observed for the fibres with AT treatment.

231 From the tabulated results, it can be seen that the HT alkali treated fibre exhibited higher average

232 tensile strength and Young's modulus compared to UT and AT alkali treated fibres, whereas the

233 average tensile strength and Young's modulus exhibited by the AT alkali treated fibre were lower

234 than for UT fibre. This suggests that the resulting structures of the treated fibres depend on the

235 alkali treatment used. The increase in average tensile strength for HT alkali treated fibre compared

236 to UT fibre is thought to be due to the removal of weak components (non-strengthening

237 components) evidenced by the fibre diameter reduction after the treatment. The removal of weak

238 components from the fibre cell walls can lead to close packing of cellulose chains and possibly a

239 decrease in the microfibrillar angle. This close compaction could have enhanced the adhesions

240 between cellulose microfibrils, thereby provided better tensile properties for HT treated fibres

241 towards the loading direction compared to UT treated fibres (Efendy and Pickering 2014). As can

242 be seen in Table 2, although the diameter of AT alkali treated fibre reduced after the treatment

243 compared to UT fibre, the tensile properties of the fibre were reduced even below that of UT fibre.

244 The decrease in tensile properties associated with the fibre is thought to be due to the degradation

245 of the crystalline cellulose chains in the microfibrils or bonding between cellulose microfibrils as

246 affected by the AT treatment (Roy, Chakraborty et al. 2012, Efendy and Pickering 2014).

247 A Student's t-test was carried out for comparing HT alkali treated fibres with different granulation

248 sequence and it was found that the sequence of granulation had no significant effect on tensile

249 properties of the fibres. Weibull modulus, Weibull characteristic strength and experimental

250 average tensile strength are displayed in Table 3. As expected, the characteristic strength has the

251 same trend as that of average tensile strength. The Weibull modulus for the fibres varied from 1.47

252 to 2.05. These values are comparable with those reported in the literature for cellulosic fibres

253 (Pickering, Beckermann et al. 2007, Ghazali and Efendy 2016).

254 Table 3: Comparison of Weibull parameters with experimental tensile strength for hemp samples

\begin{tabular}{|c|c|c|c|}
\hline Hemp Samples & Weibull Modulus, $w$ & $\begin{array}{c}\text { Characteristic Strength } \\
(\mathrm{MPa}), \sigma_{0}\end{array}$ & $\begin{array}{c}\text { Average Tensile } \\
\text { Strength (MPa) }\end{array}$ \\
\hline
\end{tabular}




\begin{tabular}{|c|c|c|c|}
\hline UT & 1.68 & 576 & 517 \\
\hline AT/one hour & 1.92 & 478 & 436 \\
\hline Granulated before HT & 2.05 & 869 & 781 \\
\hline Granulated after HT & 1.47 & 928 & 833 \\
\hline
\end{tabular}

$255 \quad 3.2$ Crystallinity index (Ic)

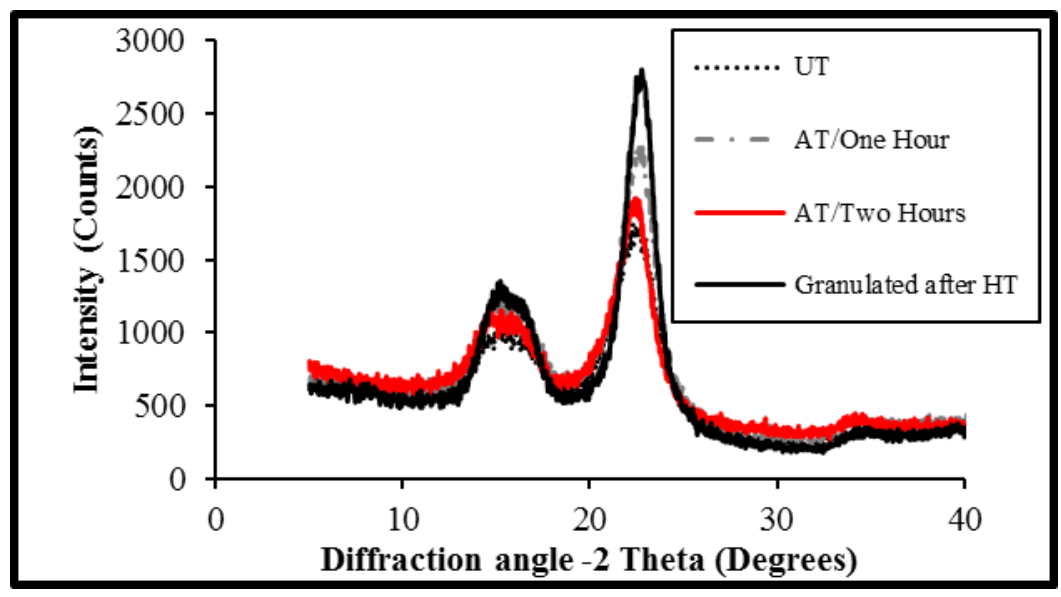

257 Fig. 7. X-ray diffraction curves for untreated, atmospheric temperature treated and high

258 temperature treated fibres.

259 Crystallinity index indicates the degree of crystallinity (Mwaikambo and Ansell 2002, Ouajai and

260 Shanks 2005). The X-ray diffraction profiles (curves) of UT, AT/one hour, AT/two hours and

261 granulated after HT treated hemp fibres are shown in Fig. 7. The $I_{c}$ values were calculated from

262 maximum and minimum intensity crystallographic peaks for each profile which are around $2 \theta=$

$26322.7^{\circ}$ and $2 \theta=18.3^{\circ}$ respectively and are displayed in Table 4.

264 Table 4: Crystallinity index for hemp samples

\begin{tabular}{|c|c|}
\hline Hemp Samples & Crystallinity Index $\left(I_{c}\right)$ \\
\hline UT & 64.87 \\
\hline AT/ One Hour & 71.16 \\
\hline AT/ Two Hours & 61.68 \\
\hline Granulated after HT & 80.65 \\
\hline
\end{tabular}

266 As can be seen in Table 4, alkali treatments improved the $I_{c}$ values except for AT/two hours. The

267 higher $I_{c}$ value of HT alkali treated fibre compared to the UT fibre would be expected due to the

268 removal of non-crystalline materials and possibly better packing of cellulose chains within the 
269 fibre (Beckermann 2007). Although the $I_{c}$ value of AT/one hour alkali treated fibres was higher

270 compared to UT fibre, as discussed earlier the tensile strength of this fibre was lower than that of

271 UT fibre. This suggests that chain scission could have overridden the influence of increased

272 crystallinity (Islam, Pickering et al. 2010, Islam, Pickering et al. 2011, Sawpan, Pickering et al.

273 2011, Ghazali and Efendy 2016). It has been reported elsewhere that the degradation rate of

274 cellulose in alkali is influenced by fibrillar morphology; a more ordered physical structure impedes

275 degradation (Knill and Kennedy 2003). This supports the production of better-packed cellulose

276 chains with HT treatment which would have impeded the diffusion of alkali reducing cellulose

277 degradation compared to AT alkali treated fibres.

\section{$278 \quad 3.3$ Infrared spectroscopic analysis}

279 Peaks (Fig. 8) in the regions $1730-1740 \mathrm{~cm}^{-1}$ and $1200-1300 \mathrm{~cm}^{-1}$ indicate the hemicellulose and

280 lignin components through the presence of $\mathrm{C}=\mathrm{O}$ linkages (Abraham, Deepa et al. 2011, Chen, Yu

281 et al. 2011). Peaks at $1737 \mathrm{~cm}^{-1}, 1252 \mathrm{~cm}^{-1}$ and $1201 \mathrm{~cm}^{-1}$ for the UT fibres, became smaller for

282 the AT alkali treated fibres and were not visible for HT alkali treated fibres. Reduction of peak

283 heights supports that alkali treatment removed hemicellulose and lignin, with more removal

284 occurring in HT alkali treated fibres compared to AT alkali treated fibres (Olsson and Salmén

285 2004, Li and Pickering 2008, Peng, Ren et al. 2009, Abraham, Deepa et al. 2011, Islam, Pickering

286 et al. 2011, Kabir, Wang et al. 2013). Similarly, the smaller peaks in the range between $1280 \mathrm{~cm}^{-1}$

287 and $1330 \mathrm{~cm}^{-1}$ for HT alkali treated fibre compared to AT alkali treated and UT fibres further

288 support that HT treatment removes more hemicellulose than AT alkali treated fibres (Taha,

289 Steuernagel et al. 2007). The intensity of peaks between $1630 \mathrm{~cm}^{-1}$ and $1650 \mathrm{~cm}^{-1}$ slightly

290 increased after alkali treatment, which may be due to water molecules formed by the reactions

291 between sodium hydroxide and cellulosic hydroxyl groups (Le Troedec, Sedan et al. 2008). 


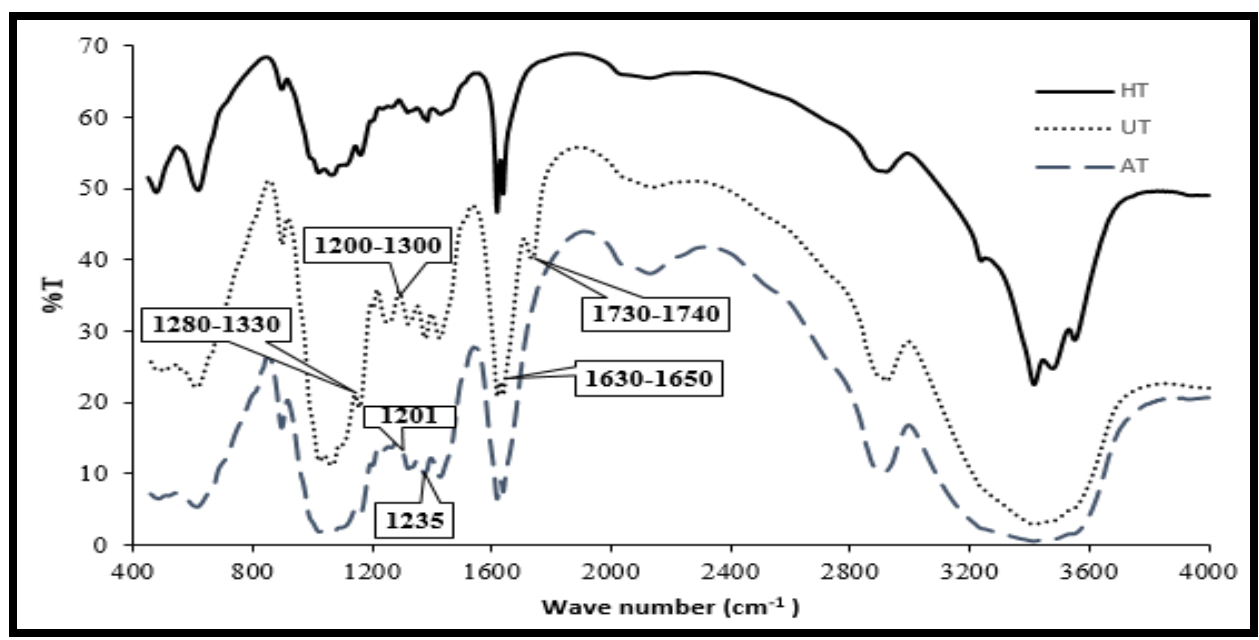

293 Fig. 8. The FTIR spectra of untreated, AT/one hour treated, and granulated after HT treated fibres.

\section{$294 \quad 3.4$ Thermal gravimetric analysis (TGA)}

295 Typically, for NPFs, there are three main stages of degradation where most of the weight loss

296 occurs: $50-100{ }^{\circ} \mathrm{C}$ due to evaporation of moisture in the fibres, $200-350{ }^{\circ} \mathrm{C}$ due to hemicellulose

297 decomposition and $300-500{ }^{\circ} \mathrm{C}$ mainly due to degradation of lignin and cellulose (Sun, Tomkinson

298 et al. 2000, Dahiya and Rana 2004, Methacanon, Weerawatsophon et al. 2010).

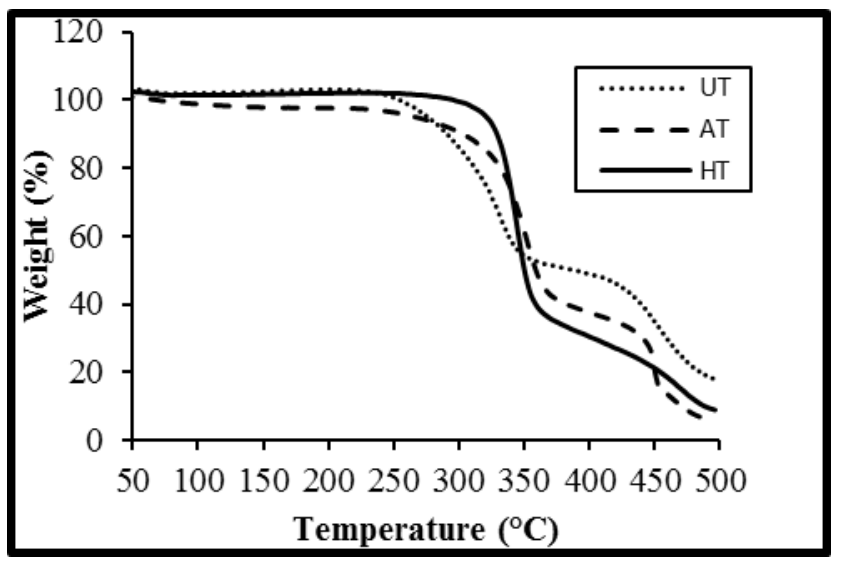

300 Fig. 9. TGA thermograms for UT, AT/one hour treated, and granulated after HT treated fibres. 


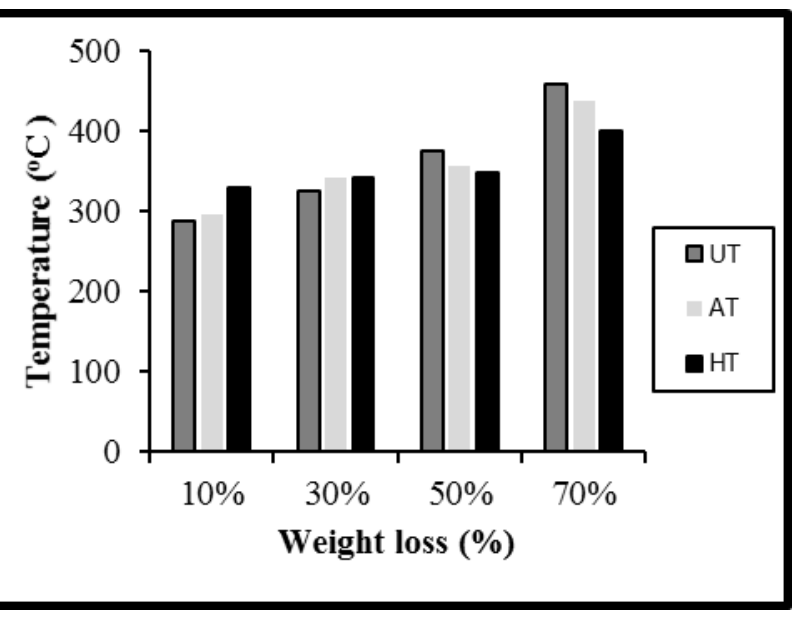

302 Fig. 10. Weight loss summary for different samples.

303 Figures 9 and 10 (Fig. 9 and Fig. 10) show the TGA thermograms and weight loss summary for

304 UT fibres, AT and HT alkali treated fibres. From Fig. 10, it can be seen that the initial $10 \%$

305 weight loss occurred only at $297^{\circ} \mathrm{C}$ and $329^{\circ} \mathrm{C}$ for the AT and HT alkali treated fibres

306 respectively compared to $288^{\circ} \mathrm{C}$ for UT fibres supporting the overall improved thermal stability of

307 the fibres. The improved thermal stability of the fibres is likely to be due to thermally unstable

308 components (hemicellulose and pectin) being removed from the fibres due to alkali treatment

309 (Beckermann 2007), with more removal occurring with HT alkali treatment compared to AT

310 treated fibres as supported by FTIR analysis. As the temperature further increased above $360^{\circ} \mathrm{C}$,

311 the weight loss was lower for UT fibres compared to treated fibres, which may be due to a stable

312 lignocellulose complex formed at higher temperatures that prevented this lignin-rich fibre from

313 further weight loss above $360^{\circ} \mathrm{C}$ (Islam 2008). Also, at higher temperatures, it was found that the

314 weight percentage loss was higher for HT alkali treated fibres compared to AT alkali treated fibres

315 (Fig. 10). This higher weight percentage loss for HT alkali treated fibres above $360{ }^{\circ} \mathrm{C}$ supports

316 that the greater removal of lignin from the fibre was by HT alkali treatment compared to AT alkali

317 treatment (Beckermann 2007, Ghazali and Efendy 2016). This greater removal was further

318 supported by the higher amount of residue obtained after the TGA analysis for AT treated fibres

319 compared to the HT treated fibres (Beg 2007). 


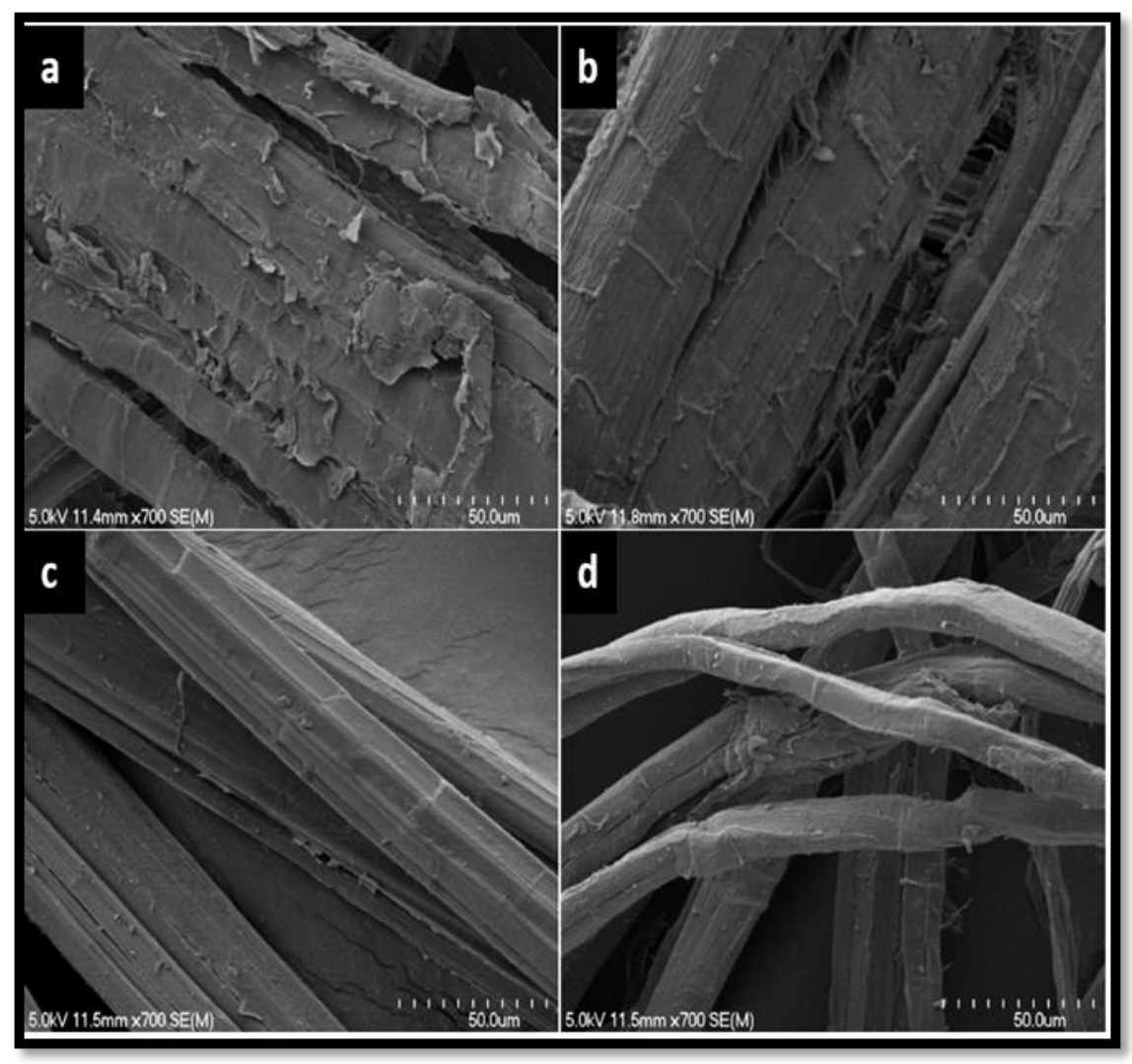

322 Fig. 11. SEM images of hemp fibre surfaces (a) UT fibre (b) AT/one hour alkali treated fibre (c) 323 granulated before HT alkali treated fibre (d) granulated after HT alkali treated fibre.

324 Fig. 11 shows the SEM micrographs of hemp fibre. As can be seen in Fig. 11a, the UT fibres are

325 mostly bundle form; substances known to include lignin, pectin, hemicellulose and other non-

326 strengthening components are localised on their surfaces (Ghazali and Efendy 2016). Alkali

327 treated hemp fibres appeared to have undergone some degree of fibre separation known to occur 328 due to the removal of some of these components (Fig. 11b, 11c and 11d). However, it was found 329 that the AT treatment resulted in very little separation of fibres compared to the HT alkali

330 treatment (Fig. 11b). It was also found that the fibres granulated after HT alkali treatment were

331 better separated compared to the fibres granulated before HT alkali treatment, which is evident

332 from Fig. 11d compared to Fig. 11c.

\section{$333 \quad 3.6$ Fibre mat assessment}

334 It was found that only fibres granulated after HT alkali treatment were sufficiently separated to 335 successfully be used in a dynamic sheet former to form short hemp fibre mats (Fig. 5a and Fig. 
336 6a). Fig. 12 shows the fibre orientation distribution profiles obtained for the mats analysed using

337 OrientationJ (ImageJ). As can be seen for the random mats, there appeared only a relatively small

338 broad peak (almost a flat curve). In contrast, there appeared a sharp predominant peak for the mats

339 produced using DSF around $0^{\circ}\left( \pm 5^{\circ}\right)$, i.e. the preferred orientation direction. The coherency

340 factors generated by the OrientationJ program for the DSF mats and random mats were $0.23( \pm$

$3410.028)$ and $0.11(0.038)$, respectively. The predominant peak and higher coherency factor for the

342 DSF mats compared to the broad peak and lower coherency factor for the random mats support the

343 potential of dynamic sheet former to produce aligned short hemp fibre mats.

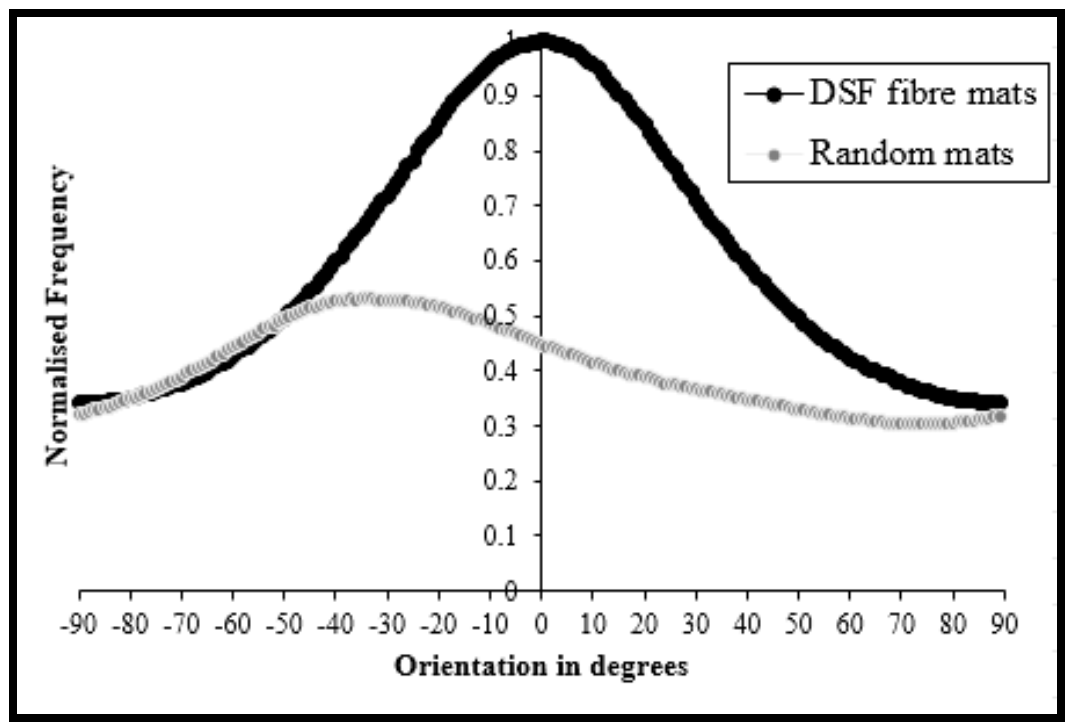

345 Fig. 12. Fibre orientation distribution profiles obtained by OrientationJ.

\section{$346 \quad 3.7$ Evaluation of composites}

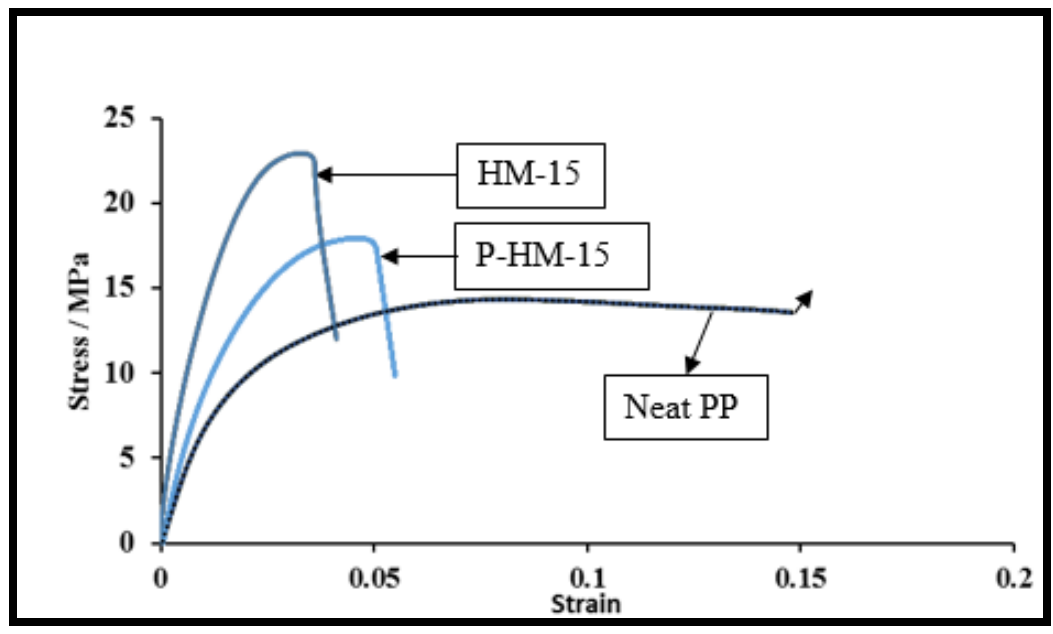

348 Fig. 13. Typical stress-strain curves for polypropylene reinforced with $15 \mathrm{wt} \%$ hemp fibre loaded 349 parallel and perpendicular to the DSF rotation (main fibre orientation) direction. 

rotation direction). Fig. 13 shows the stress versus strain curves for the composites with fibre

352 content of $15 \mathrm{wt} \%$ along with that of neat PP for comparison purposes. Neat PP extended in a

353 ductile manner to high strain without fail, whereas the incorporation of fibres caused PP to fail in

354 almost a brittle manner without much noticeable yielding.

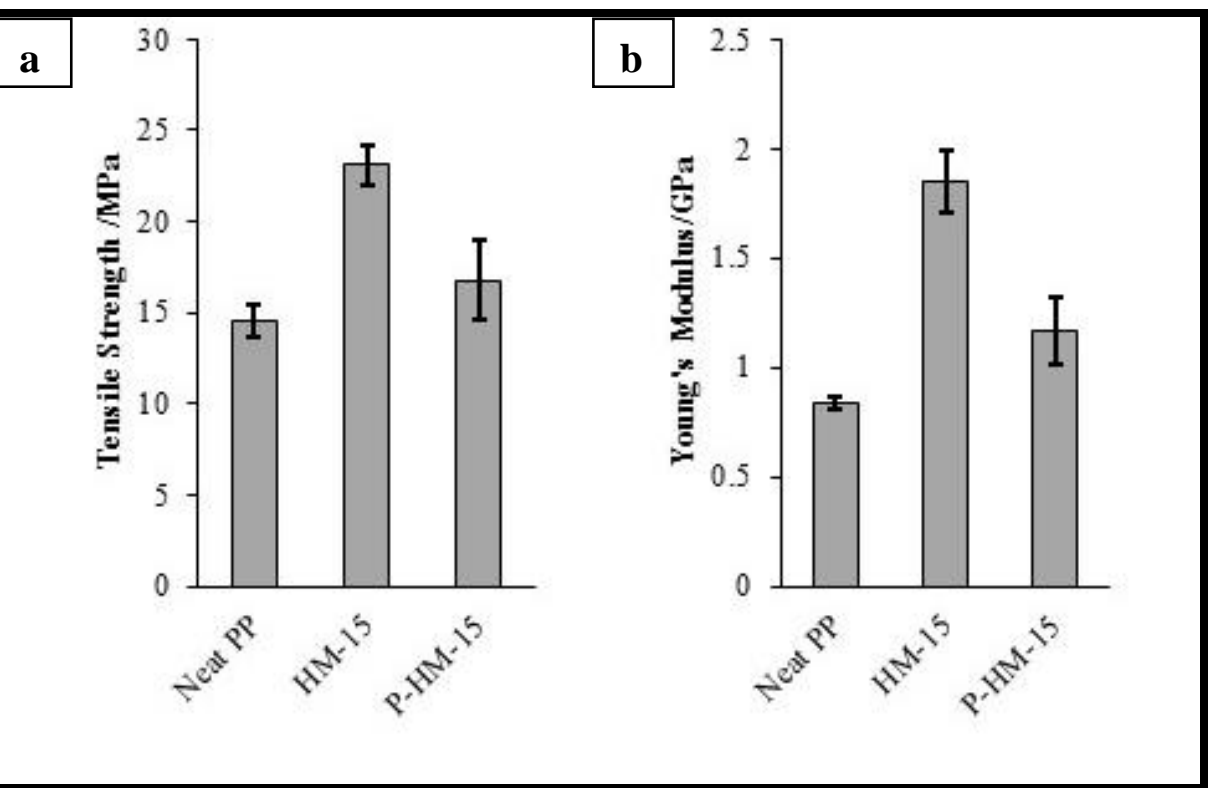

356 Fig. 14. Graph representing (a) tensile strength and (b) Young's modulus for the hemp composites 357 tested parallel and perpendicular to the DSF rotation direction.

358 Tensile properties for neat PP along with composites are presented in Fig. 14. The maximum 359 tensile strength and Young's modulus of the composite were approximately 59 and $120 \%$ higher 360 than for neat PP. From the results, it can be seen that composite tested parallel to the main fibre

361 orientation direction exhibited higher tensile properties compared to the composite tested

362 perpendicular to the main fibre orientation direction. This further supports the potential of DSF to

363 produce aligned fibre mats. It has been reported that the best mechanical properties for composites

364 are generally being obtained when the fibres are aligned parallel to the direction of the applied

365 load (Herrera-Franco and Valadez-Gonzalez 2005, Pickering, Efendy et al. 2015).

\section{4. Conclusion}

367 The high temperature treatment at $120{ }^{\circ} \mathrm{C}$ using $5 \mathrm{wt} \% \mathrm{NaOH}$ and $2 \mathrm{wt} \% \mathrm{Na}_{2} \mathrm{SO}_{3}$, with a fibre to

368 solution ratio of 1:8, improved the tensile strength and Young's modulus of hemp fibres by $51 \%$

369 and $62 \%$ respectively compared to untreated fibre. In contrast, tensile strength and Young's 
$37116 \%$ and $14 \%$ respectively. SEM, XRD, FTIR and TGA analyses support that the high

372 temperature treatment removes more non-strengthening components from the fibres compared to

373 ambient temperature treatment. Improvement of fibre strength with high temperature alkali

374 treatment compared with the reduction of fibre strength obtained with ambient temperature alkali

375 treatment suggests better packing of cellulose chains occur for high temperature treatment

376 providing better resistance to cellulose degradation. Therefore, high temperature treatment is

377 recommended for producing strong and stiff fibres for use in natural plant fibre composites.

378 Overall, significantly aligned short hemp fibre mats from high strength hemp fibres was produced

379 using DSF.

\section{Acknowledgements}

381 This research received no specific grant from any agency in the public, commercial, or not-for-

382 profit sectors. However, the authors would like to thank to the University of Waikato's

383 Composites research group for their support.

\section{References}

385 Abraham, E., B. Deepa, L. Pothan, M. Jacob, S. Thomas, U. Cvelbar and R. Anandjiwala (2011).

386 "Extraction of nanocellulose fibrils from lignocellulosic fibres: a novel approach." Carbohydrate

387 Polymers 86(4): 1468-1475.

388 Abràmoff, M. D., P. J. Magalhães and S. J. Ram (2004). "Image processing with ImageJ."

389 Biophotonics international 11(7): 36-42.

390 ASTM, D. (1986). "3379-75." Standard Test Method for Tensile Strength and Young's Modulus 391 for High-Modulus Single-Filament Materials, Annual Book of ASTM Standards,(May 1989) 8: 392 128-131.

393 Beckermann, G. (2007). "Performance of hemp-fibre reinforced polypropylene composite

Beckermann, G. and K. L. Pickering (2008). "Engineering and evaluation of hemp fibre reinforced polypropylene composites: fibre treatment and matrix modification." Composites Part A: Applied Science and Manufacturing 39(6): 979-988.

Beg, M. D. H. (2007). The improvement of interfacial bonding, weathering and recycling of wood fibre reinforced polypropylene composites, The University of Waikato.

Biagiotti, J., D. Puglia, L. Torre, J. M. Kenny, A. Arbelaiz, G. Cantero, C. Marieta, R. Llano-Ponte and I. Mondragon (2004). "A systematic investigation on the influence of the chemical treatment of natural fibers on the properties of their polymer matrix composites." Polymer Composites 25(5): 470-479.

Bledzki, A. and J. Gassan (1999). "Composites reinforced with cellulose based fibres." Progress in polymer science 24(2): 221-274.

Chen, W., H. Yu, Y. Liu, P. Chen, M. Zhang and Y. Hai (2011). "Individualization of cellulose nanofibers from wood using high-intensity ultrasonication combined with chemical pretreatments." Carbohydrate Polymers 83(4): 1804-1811.

412 Efendy, M. A. and K. Pickering (2014). "Comparison of harakeke with hemp fibre as a potential 413 reinforcement in composites." Composites Part A: Applied Science and Manufacturing 67: 259- 
French, A. D. (2014). "Idealized powder diffraction patterns for cellulose polymorphs." Cellulose 416 21(2): 885-896.

417 Gesellchen, F., A. Bernassau, T. Dejardin, D. Cumming and M. Riehle (2014). "Cell patterning 418 with a heptagon acoustic tweezer-application in neurite guidance." Lab on a Chip 14(13): 22664192275

420 Ghazali, M. and A. Efendy (2016). Bio-composites materials from engineered natural fibres for structural applications, University of Waikato.

Herrera-Franco, P. and A. Valadez-Gonzalez (2005). "A study of the mechanical properties of short natural-fiber reinforced composites." Composites Part B: Engineering 36(8): 597-608.

Islam, M., K. Pickering and N. Foreman (2010). "Influence of alkali treatment on the interfacial and physico-mechanical properties of industrial hemp fibre reinforced polylactic acid composites." Composites Part A: Applied Science and Manufacturing 41(5): 596-603.

Islam, M. S. (2008). The influence of fibre processing and treatments on hemp fibre/epoxy and hemp fibre/PLA composites, the University of Waikato.

Islam, M. S., K. L. Pickering and N. J. Foreman (2011). "Influence of alkali fiber treatment and fiber processing on the mechanical properties of hemp/epoxy composites." Journal of Applied Polymer Science 119(6): 3696-3707.

John, M. J. and R. D. Anandjiwala (2008). "Recent developments in chemical modification and characterization of natural fiber-reinforced composites." Polymer composites 29(2): 187-207.

Kabir, M., H. Wang, K. Lau and F. Cardona (2012). "Chemical treatments on plant-based natural fibre reinforced polymer composites: An overview." Composites Part B: Engineering 43(7): 28832892.

Kabir, M., H. Wang, K. Lau and F. Cardona (2013). "Effects of chemical treatments on hemp fibre structure." Applied Surface Science 276: 13-23.

Kabir, M., H. Wang, K. Lau and F. Cardona (2013). "Tensile properties of chemically treated hemp fibres as reinforcement for composites." Composites Part B: Engineering 53: 362-368.

Kabir, M., H. Wang, K. Lau, F. Cardona and T. Aravinthan (2012). "Mechanical properties of chemically-treated hemp fibre reinforced sandwich composites." Composites Part B: Engineering 43(2): 159-169.

Knill, C. J. and J. F. Kennedy (2003). "Degradation of cellulose under alkaline conditions." Carbohydrate Polymers 51(3): 281-300.

Le, T. M. (2016). Harakeke fibre as reinforcement in epoxy matrix composites and its hybridisation with hemp fibre, University of Waikato.

Le, T. M. and K. L. Pickering (2015). "The potential of harakeke fibre as reinforcement in polymer matrix composites including modelling of long harakeke fibre composite strength." Composites Part A: Applied Science and Manufacturing 76: 44-53.

Le Troedec, M., D. Sedan, C. Peyratout, J. P. Bonnet, A. Smith, R. Guinebretiere, V. Gloaguen and P. Krausz (2008). "Influence of various chemical treatments on the composition and structure of hemp fibres." Composites Part A: Applied Science and Manufacturing 39(3): 514-522.

Lewis, D. D. J. (2016). Interlaminar reinforcement of carbon fiber composites from unidirectional prepreg utilizing aligned carbon nanotubes, Massachusetts Institute of Technology.

Li, X., L. G. Tabil and S. Panigrahi (2007). "Chemical treatments of natural fiber for use in natural fiber-reinforced composites: a review." Journal of Polymers and the Environment 15(1): 25-33.

Li, Y. and K. L. Pickering (2008). "Hemp fibre reinforced composites using chelator and enzyme treatments." Composites Science and Technology 68(15): 3293-3298.

Methacanon, P., U. Weerawatsophon, N. Sumransin, C. Prahsarn and D. Bergado (2010). "Properties and potential application of the selected natural fibers as limited life geotextiles." Carbohydrate Polymers 82(4): 1090-1096.

Mwaikambo, L. Y. and M. P. Ansell (2002). "Chemical modification of hemp, sisal, jute, and kapok fibers by alkalization." Journal of applied polymer science 84(12): 2222-2234.

Olsson, A.-M. and L. Salmén (2004). "The association of water to cellulose and hemicellulose in paper examined by FTIR spectroscopy." Carbohydrate research 339(4): 813-818.

Ouajai, S. and R. Shanks (2005). "Composition, structure and thermal degradation of hemp cellulose after chemical treatments." Polymer degradation and stability 89(2): 327-335.

Oushabi, A., S. Sair, F. O. Hassani, Y. Abboud, O. Tanane and A. El Bouari (2017). "The effect of alkali treatment on mechanical, morphological and thermal properties of date palm fibers (DPFs): Study of the interface of DPF-Polyurethane composite." South African Journal of Chemical Engineering 23: 116-123.

Palmieri, V., D. Lucchetti, A. Maiorana, M. Papi, G. Maulucci, F. Calapà, G. Ciasca, R. Giordano, A. Sgambato and M. De Spirito (2015). "Mechanical and structural comparison between primary tumor and lymph node metastasis cells in colorectal cancer." Soft matter 11(28): 5719-5726. 

hemicelluloses obtained by graded ethanol precipitation from sugarcane bagasse." Journal of agricultural and food chemistry 57(14): 6305-6317.

479 Pickering, K. (2008). Properties and performance of natural-fibre composites, Elsevier.

480 Pickering, K., G. Beckermann, S. Alam and N. Foreman (2007). "Optimising industrial hemp fibre

481 for composites." Composites Part A: Applied Science and Manufacturing 38(2): 461-468.

482 Pickering, K. and M. A. Efendy (2016). "Preparation and mechanical properties of novel bio483 composite made of dynamically sheet formed discontinuous harakeke and hemp fibre mat 484 reinforced PLA composites for structural applications." Industrial Crops and Products 84: 139485150

486 Pickering, K., M. A. Efendy and T. Le (2015). "A review of recent developments in natural fibre composites and their mechanical performance." Composites Part A: Applied Science and Manufacturing.

Pickering, K. and T. M. Le (2016). "High performance aligned short natural fibre-Epoxy composites." Composites Part B: Engineering 85: 123-129.

Püspöki, Z., M. Storath, D. Sage and M. Unser (2016). Transforms and operators for directional bioimage analysis: a survey. Focus on Bio-Image Informatics, Springer: 69-93. Rezakhaniha, R., A. Agianniotis, J. T. C. Schrauwen, A. Griffa, D. Sage, C. v. Bouten, F. Van de Vosse, M. Unser and N. Stergiopulos (2012). "Experimental investigation of collagen waviness and orientation in the arterial adventitia using confocal laser scanning microscopy." Biomechanics and modeling in mechanobiology 11(3-4): 461-473.

498 "Improvement in mechanical properties of jute fibres through mild alkali treatment as 499 demonstrated by utilisation of the Weibull distribution model." Bioresource technology 107: 222500228

501 Sawpan, M. A., K. L. Pickering and A. Fernyhough (2011). "Effect of various chemical treatments 502 on the fibre structure and tensile properties of industrial hemp fibres." Composites Part A: Applied 503 Science and Manufacturing 42(8): 888-895.

504 Schneider, C. A., W. S. Rasband and K. W. Eliceiri (2012). "NIH Image to ImageJ: 25 years of 505 image analysis." Nature methods 9(7): 671-675.

506 Segal, L., J. Creely, A. Martin Jr and C. Conrad (1959). "An empirical method for estimating the 507 degree of crystallinity of native cellulose using the X-ray diffractometer." Textile research journal 508 29(10): 786-794.

509 Shah, D. U., F. Vollrath, J. Stires and D. D. Deheyn (2015). "The biocomposite tube of a 510 chaetopterid marine worm constructed with highly-controlled orientation of nanofilaments." 511 Materials Science and Engineering: C 48: 408-415.

512 Sun, R., J. Tomkinson and G. L. Jones (2000). "Fractional characterization of ash-AQ lignin by 513 successive extraction with organic solvents from oil palm EFB fibre." Polymer Degradation and 514 Stability 68(1): 111-119.

515 Sunny, T., K. L. Pickering and S. H. Lim (2017). Alignment of Short Fibres: An Overview. 516 Processing and Fabrication of Advanced Materials-XXV.

517 Sunny, T., K. L. Pickering and S. H. Lim (2018). Fibre Orientation Distribution Assessment of 518 Dynamically Sheet Formed Hemp Fibre Mats by Image Analysis. Applied Mechanics and 519 Materials, Trans Tech Publ.

520 Taha, I., L. Steuernagel and G. Ziegmann (2007). "Optimization of the alkali treatment process of 521 date palm fibres for polymeric composites." Composite Interfaces 14(7-9): 669-684.

522 Zafeiropoulos, N. and C. Baillie (2007). "A study of the effect of surface treatments on the tensile 523 strength of flax fibres: Part II. Application of Weibull statistics." Composites Part A: Applied 524 Science and Manufacturing 38(2): 629-638. 